\title{
Participatory Methods in the Georgian Caucasus: Understanding Vulnerability and Response to Debrisflow Hazards
}

\author{
Valentina Spanu ${ }^{1 *}$, George Gaprindashvili2,3, Michael Keith McCall ${ }^{4}$ \\ ${ }^{1}$ CRS4, Loc. Piscina Manna, Pula, Italy \\ ${ }^{2}$ Ministry of Environment and Natural Resources Protection of Georgia, LEPL National Environmental Agency, \\ Department of Geology, Tbilisi, Georgia \\ ${ }^{3}$ Ivane Javakhishvili Tbilisi State University, Tbilisi, Georgia \\ ${ }^{4}$ CIGA-UNAM, Universidad Nacional Autónoma de México, Antigua Carretera a Pátzcuaro No. 8701, Col. \\ Ex-Hacienda de San José de la Huerta, Morelia, México \\ Email: *vale.spanu@tiscali.it, gaprindashvili.george@gmail.com, mccall@ciga.unam.mx
}

Received 30 May 2015; accepted 18 July 2015; published 22 July 2015

Copyright (C) 2015 by authors and Scientific Research Publishing Inc.

This work is licensed under the Creative Commons Attribution International License (CC BY). http://creativecommons.org/licenses/by/4.0/

(C) (i) Open Access

\section{Abstract}

Assessment and emergency planning to cope with disaster risks are usually founded primarily on expert evaluations, in part because local governments and public bodies mainly finance the recovery activities. Local communities affected by disasters are scarcely really involved in the processes of information collection, problem analysis, or design of emergency plans. However, the development of good practices for incorporating local people's knowledge into disaster risk management, known as Community-Based Disaster Risk Management (CBDRM), is becoming more common. Scientific communities increasingly realize the importance of local knowledge, though in Georgia this is still uncommon. Georgia faces frequent natural disasters and threats to its fragile ecosystems caused by unsustainable natural resource management and agricultural practices, improper infrastructure and urban development, as well as by innate geological and climatic factors. In this context, the lack of communication between local communities and public administrations is absolutely deleterious. The article analyzes the effectiveness of participatory methods and tools for better comprehension of people's vulnerability and responses. Fieldwork in mountain areas of Caucasus involved local communities to investigate the direct participation of local people in Disaster Risk Management and assess their availability and interest to engage in hazard mapping and risk responses.

${ }^{*}$ Corresponding author.

How to cite this paper: Spanu, V., Gaprindashvili, G. and McCall, M.K. (2015) Participatory Methods in the Georgian Caucasus: Understanding Vulnerability and Response to Debrisflow Hazards. International Journal of Geosciences, 6, 666-674. 


\section{Keywords}

\section{Participatory Methods, PGS, Debrisflow, Vulnerability, Local Knowledge, Cyber Tracker}

\section{Introduction}

In October 2010, a workshop has been carried out in Bulachauri, Georgia, in order to teach those who work with local authorities and governments how to approach the communities affected by disasters related to slope instability, how to get useful information and how to work together with them for disaster prevention and management. Some fieldworks have been done specifically to check the level of trust of the local communities toward the above mentioned institutions, the reliability in giving useful information and the availability in collaborating with NGOs and local governments in order to reduce the risk of disasters in the future and reconstruct the destroyed areas.

Activities were focused on institutional capacity building in disaster risk reduction via introduction of modern spatial approaches and technologies and the development of risk communication strategy in spatial planning.

The program CyberTracker has been used as main tool for communication, as a bridge to help connect local governments and experts as stakeholders interested in receiving information to face the problem, and the people directly affected by the problem as injured party interested in providing the correct information in order to receive the proper help. CyberTracker is a method of field data collection and it allows the record of large quantities of geo-referenced data for field observations at a high speed and level of detail. This program enhances the communication with the people even if the mother tongue is different thanks to special officially recognized icons, maps and graphs allowing the investigator to ask for information, and the local interlocutor to answer in a quite detailed way.

\section{Natural Hazards, Vulnerability and Coping Capacities in Mountain Areas}

Before to proceed with the key points of the work, it is appropriate to explain the concepts on which the entire work is set up. Hazards, vulnerabilities, coping/adaptation (and resilience) and disaster risks, are inter-related/ inter-dependent concepts. Hazards, which may or may not lead to disasters (events that overcome the abilities and capacities of people and institutions to recover), can emanate from both physical and social-political causes; there are no purely "natural" hazards. There are multiple factors at play, not just geological hazards or atmospheric events. It is the complex interaction of different processes, many of them having social origins, which makes people more or less vulnerable.

Vulnerability is a complex socio-environmental process that makes people differentially susceptible to disaster risk, creating uneven outcomes within and between communities [1]. It is highly differentiated and determined by physical location, economic conditions, social-cultural structures, institutional capacities, and specific history, a social process that involves political, economic and social issues [2]-[4]. Mountain regions have high vulnerability due to their high altitude settings. Very frequently, due to their low accessibility and overall isolation, these are high-risk areas where relatively small hazards can trigger economic damage, physical destruction, human injury and death.

Vulnerability may be counteracted by individual, group or community capacity for protective or mitigating actions, or by larger entities such as NGOs or governments that provide support [4] [5]. These coping capacities change the status of vulnerabilities. Coping capacities are determined by economic conditions, social-cultural structures and networks, institutional capacities and specific history.

Coping mechanisms in mountain areas are developed by local populations over long periods as they experience hazards more frequently. They display a combination of "trial and error" methods developed by experimentation, plus methods learnt from other communities and outside sources.

Natural processes do not necessarily result in a disaster. The risk of the disaster comes when an event arises in a human situation, affecting people, infrastructure and the social fabric of a community. Disasters expose the structural conditions underlying a society, including spatial drivers whereby poverty inequalities push marginalized communities into (interstitial and isolated) mountain spaces. 


\section{People's Perceptions and Response to Risk and Community-Based Disaster Risk Management}

Risk perceptions and responses are influenced by socio-demographic variables [6] changing according to gender, age, cultural background and education. Understanding people's perception of their risk to natural disasters is fundamental to evaluate their vulnerability and responses, designing effective warnings, encouraging residents to take preparedness steps, and developing emergency management plans [7].

The participation of local people in hazard mapping, planning and monitoring is becoming an essential solution for a better understanding of their own territory and its dynamics [8]-[13]. When a disaster occurs, communities are typically the first line of defence [14].

Disaster Risk Reduction Management (DRRM) aims to minimize vulnerabilities and disaster risks throughout society in order to limit the adverse impacts of hazards and to facilitate sustainable recovery [15]. This includes the handling of decisions, organization, operational skills and implementing policies, strategies, and building the coping capacities of society and communities [15] (UN-ISDR, 2004). Experts working in DRRM increasingly involve "at risk" communities in the evaluation process who become actively engaged in the identification, analysis, treatment, monitoring and evaluation of disaster risks [14]. When local people are at the heart of decision-making and implementation of DRM activities, the process is termed Community-based DRRM (CBDRRM) [14].

\section{Case Study of Mleta Village, Dusheti Municipality, Georgia}

Many areas of Georgia are at risk of Debrisflow, as shown in Figure 1.

Two seasons are critical for Debrisflows and landslides in Georgia: spring, when the snow starts melting because the temperature increases and the rivers become flooded, and autumn, when the rainy season starts. In these two periods many rural villages are severely affected by landslides and Debrisflows [16].

In 2010, The project "Institutional Building for Natural Disaster Risk Reduction (DRR) in Georgia”, financially supported by Social Transformation Programme for Central and Eastern Europe (MATRA) of the Netherlands Ministry of Foreign Affairs focussed on Mleta village in the Caucasus Mountains $\left(42^{\circ} 02^{\prime} 09.70 " \mathrm{~N}\right.$; $44^{\circ} 45^{\prime} 38.87 " \mathrm{E}$ ), selected for its location, social fabric and history of events. It represents the typical rural village of the Caucasus, where the inhabitants are now mainly elderly people and families carrying on the rural traditional activities of agriculture and sheep farming. The younger generation tends to live in the capital Tbilisi, where employment opportunities are wider, and thus the rural mountain population decreases. Those who live in

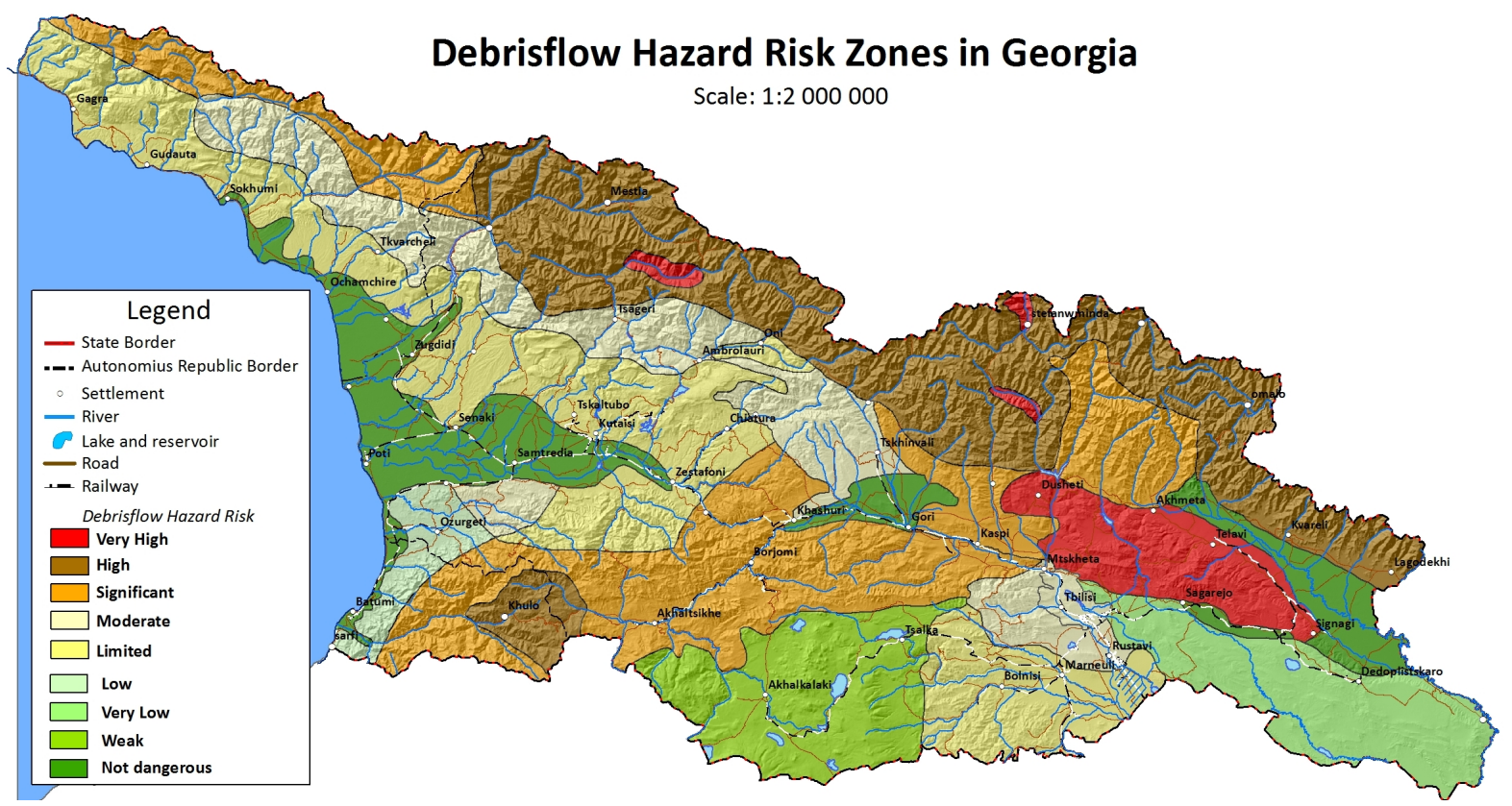

Figure 1. Debrisflow Risk Map in Georgia (Authors: Tsereteli, Gaprindashvili). 
the capital come back only occasionally, as happened after the mudslide event of 2010, to help in rebuilding houses and services and to reinforce them before the winter season. Mleta has a very high exposure to risk but there are very few preventative measures in place; emergency plans and information programs to avoid or reduce the losses do not exist.

Debrisflow risk is critical in Dusheti Region where the villages of Zemo Mleta (Upper Mleta) and Kvemo Mleta (Lower Mleta) are located; they are entirely surrounded by unstable slopes that often create mudslides, landslides and floods. Dusheti Region is bordered in the north by the main Caucasian range. The Aragvi river basin has many streams with high erosion rates producing V-shaped valleys; in the upper parts, the rivers have a $15-20 \mathrm{~m} / \mathrm{sec}$. discharge, and at the streams' tail they produce fans of transported mass materials.

The case study area can be seen in Figure 2; the two villages of Kvemo Mleta and Zemo Mleta are separated by the Mletiskhevi River, an affluent located on the right bank of the White Aragvi River, with a total basin area of $0.8 \mathrm{sq}$. km and length of $1.8 \mathrm{~km}$. The basin slopes are steep, extending south-west/north-east (length $2.4 \mathrm{~km}$, width $1.4 \mathrm{~km}$ ). The entire area is rich in active landslides and canyons, and some areas present other forms of erosion phenomena. The geology is almost entirely sedimentary rocks (from Lower Cretaceous to Quaternary), except for the volcanic plutons in the north of the region.

The severe events of 2006 and 2010 shifted millions of cubic meters of deposits of gravel, sand and even large boulders. The 2006 event happened during spring, in the first days of May, depositing 1.5 million cubic meters of sediment. The Debrisflows covered the church and two houses on the left side of the ravine.

On $24^{\text {th }}$ April 2010, around 10 a.m., water mixed with debris, mud, gravels and large boulders, burst on the village of Mleta. This was the result of very abundant rain, $23.5 \mathrm{~mm}$ in one day. The village was exposed to the double hazard of the river and material coming down from Lomisi Mountain behind the village. The Debrisflow reached the Georgian Military Highway beyond the village; the course of the Aragvi River was shifted towards the highway bridge's pillars and strong lateral erosion of the riverbank induced a partial collapse of the highway.

Debrisflows blocked the Aragvi riverbed for some time, backing up the river and causing flooding. The first floors of at least 15 houses were left standing in the riverbed and nine houses were destroyed by the Debrisflow. Crops, livestock and poultry were lost, the floods spoiled local residents' food supplies and several families became homeless. The Saint Giorgi church, destroyed during the event of 2006, was again damaged in 2010 [17].

The images (Figure 3 \& Figure 4, Source: NEA 2010) show the village of Mleta in June 2009 and after the event of 2010: (Figure 3 \& Figure 4).

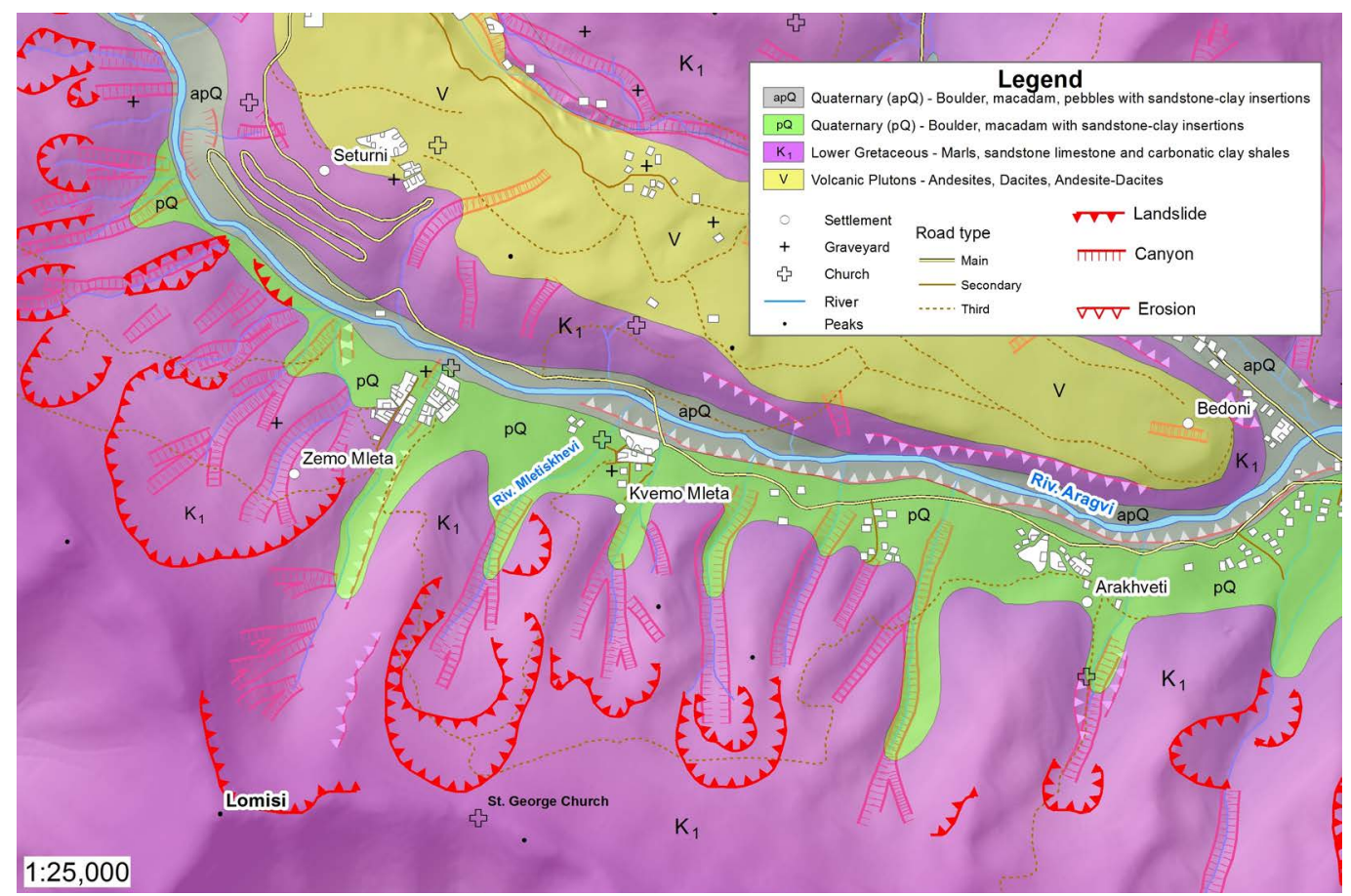

Figure 2. Geological and geomorphological context of the study area. 


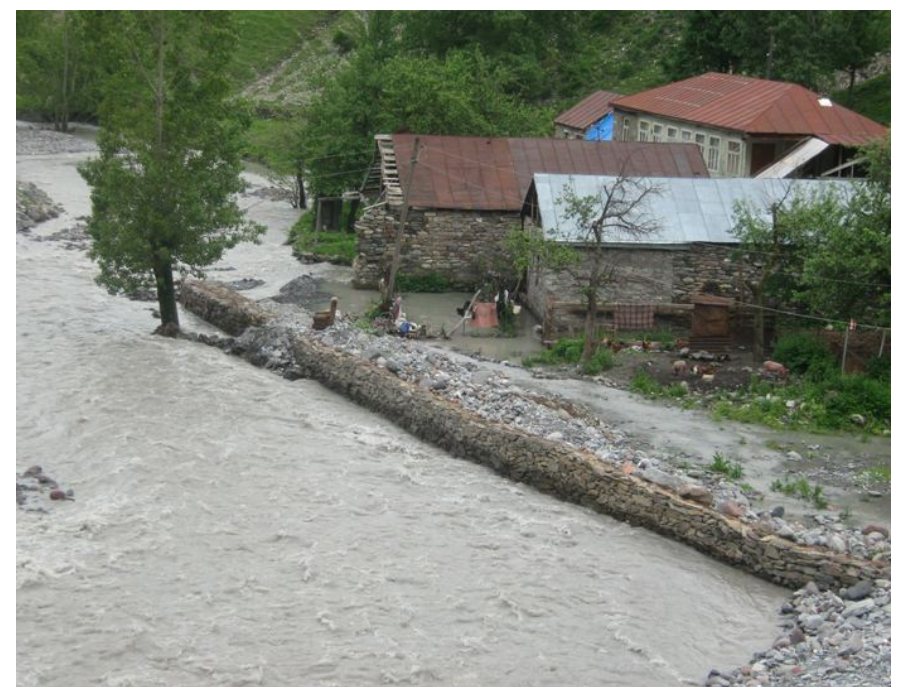

Figure 3. The situation in 2009 (June).

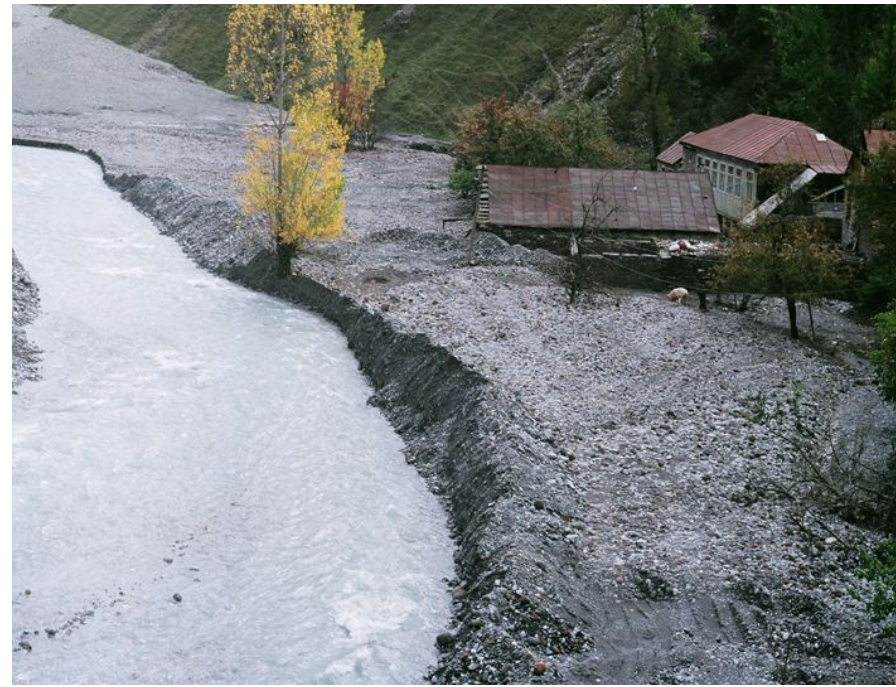

Figure 4. The situation in 2010 (September).

\section{Participatory Methodology for Eliciting Local Knowledge}

Using science and traditional knowledge together in co-management or participatory action research can be a powerful tool to improve the effectiveness of DRRM. It depends on a relationship based on trust and respect for each other's information and knowledge, and it requires different methodologies.

The fieldwork tested the use of Participatory Rural Appraisal methods (PRA) [12], in two days of intensive surveys in Upper and Lower Mleta with local people using semi-structured interviews, open-ended questions, discussions, key informants and recording household information. Local information always comes with subjective evaluations: water level can be perceived high by a child but shallow by an adult. The surveyor should always take into consideration that the same information can be told from different points of view.

The surveys worked with two sets of actors:

1) The local population of Mleta directly affected by the hazards;

2) Representatives from Georgian agencies and institutions who were engaged in social surveys with the first group.

In particular the surveys utilised CyberTracker [18], a still-developing technology for spatializing, geolocating and data collection. 
Familiarity with CyberTracker was achieved in two days of intensive surveys in Upper and Lower Mleta by the institutional actors with local people, using semi-structured interviews, open-ended questions, discussions, key informants, and recording household information on hand-held computing devices (e.g. smart phones).

The institutional actors talked directly to the Mleta village inhabitants, collecting photos, tracking, and recording information about the critical problems that people had to cope with during the extreme event of only a few months earlier. Community members willingly cooperated with the surveyors in providing useful information about the hazards, the past events, and their internal organizational capacities for first response and reconstruction.

\section{Results and Discussion}

Mleta has a high exposure to floods and debrisflows, and this relatively high occurrence of natural hazards is exacerbated by the people's perception that the government ignores their plight and abandons them (Fieldwork results, Oct 2010). The village provides a good example of local coping capacity and resilience in recovering basic services like schools and churches, and reinforcing buildings before the autumn. The community collaborates in these activities for the general benefit.

Accessibility is an endemic problem: Dusheti District administration does not have enough money to rebuild infrastructure, so when the roads within the villages and up the mountainside are damaged and impracticable, the villagers are "trapped”. In these mountainous areas it is difficult to reach remote rural communities; first-aid vehicles trying to navigate roads and bridges are totally blocked by boulders, water or mud.

Perceptions vary depending on such characteristics as gender, age, education, and cultural background. Religious people had a perception of the causes of the disaster and how to deal with them, which was totally different from the farmers' perception, or children perception of the risk. DRRM researchers and planners collecting information therefore need to appreciate the understandings of different actors, and filter what it is relevant for emergency planning and capacity-building.

CyberTracker was tested for its effectiveness in the collection and analysis of people's spatial knowledge of local (debrisflow) hazards, their vulnerabilities and their responses in risk-prone mountain villages-in a meaningful way that will help formulate measures for risk reduction.

The CyberTracker open source programme can be downloaded from internet into ICT (Information and Communication Technology) devices like IPaqs (as used by the participants during the fieldwork) or any smartphone [19]. When downloaded, CyberTracker supports and simplifies information exchange because it has been designed to be easily adopted. Using symbols and icons, people who are illiterate or speak different languages, can easily communicate through this program. It is also possible to record sounds and upload photos. Surveys need to be carried out rapidly but accurately-this methodology optimizes field survey time and provides reliable and detailed information to those who need to create emergency plans.

CyberTracker has definite advantages compared to traditional acquisition methods: first of all it is possible to store a large amount of data in a compact device, instead of carrying paper copies, and more than this, the ability to check the reliability of data inputs. There is a continuous record or the geographical position (the tracking) registered by the GPS which means more accuracy in the survey. Communicating with local people is facilitated because CyberTracker provides a wide choice of icons and sketches; it is possible to associate every record of information to pictures and sounds and/or videos. This makes the whole process more complete, including the monitoring.

Trained people_-some from government and others with more technical expertise-managed to handle the programme quite easily. In their opinion it would be good to have a close cooperation with community representatives to teach how to use the programme themselves, and enable them to collect data in their territory, especially during the critical hazard periods. Since it is possible to have several sequences in the program, variations in time and space can be registered in order to analyse the changes in the precarious risk balance of the territory (Figure 5). The fieldwork found that community members were willing to communicate their information and to collaborate in data and information collection. This was valid for people of all ages and genders.

Compared to methods previously used in vulnerability reduction plans, the participatory approach is a significant complementary tool for the expert in order to evaluate situations and support local governments in decision making. 


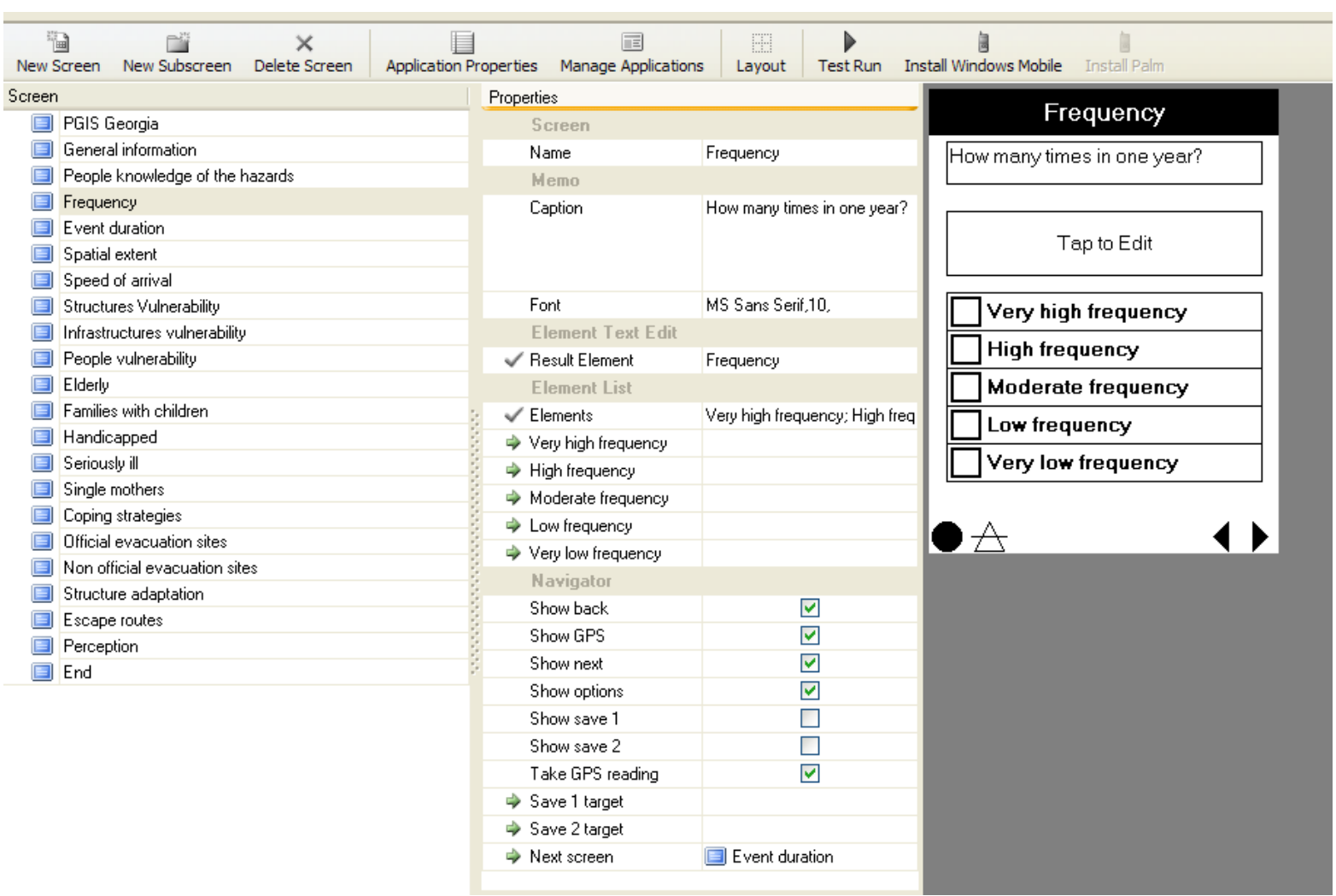

Figure 5. CT sequence used during information collection in Mleta.

Participatory approaches in the Georgian Caucasus have been successfully tested for conflict analysis in the border regions with Russia [20], for promotion of food security, regional cooperation and stability in the Southern Caucasus [21] [22], and for the management of protected areas and eco-tourism development [23] [24].

Findings result from the Mleta study, but in this case the use of CyberTracker as ICT demonstrated that it is possible to speed up all the work: from the preliminary stage of surveying the territory to information collection and, eventually, the monitoring of the area.

\section{Conclusions and Recommendations}

Local government staff and NGOs have the capacity to be much more involved in the processes of monitoring hazards, assessing vulnerability and making emergency plans.

Complementing this, mountain community members can participate in: 1) providing spatial and historical knowledge of (extreme) events and their impacts; 2) exposing the specificities of differential vulnerability of people and places; and 3) explaining details of local coping mechanisms. Since the main activities are agriculture and sheep farming, local people walk in the village environs every day. Any small changes in the river beds, such as flow variation or turbidity or, on the mountainsides, such as unusual acceleration of soil creep, are detected at the earliest stage, certainly before any experts.

This communication is essential if external experts and local governments want to understand better the local situation and move towards effective disaster risk reduction. This is a good basis to start a proper collaboration with technicians and local government who are the actors tasked with realising emergency and prevention plans. They need to interact with the locals to access information and make regular tracking surveys, and to explain to people how to monitor systematically the environment where they live every day.

CyberTracker is suitable in this context, not only for the data collection and locational data, communication instrument understandable for different stakeholders. CyberTracker is a useful tool helping the experts on disasters and technicians to have a "bridge” role, mediating between local people and government, and validating lo- 
cal spatial knowledge, in addition to being an instrument that speeds up the survey process.

Giving the local authorities, and eventually the communities, such a tool will enhance their awareness of the local environment. Whilst they are carrying out quotidian activities, they are at the same time patrolling the area and therefore making better assessments of the exposure of their territory and settlements to hazards, and a fuller understanding of the many facets of their vulnerability.

\section{Acknowledgements}

The authors would like to thank Department of Geology of National Environmental Agency of Ministry of Environment and Natural Resources Protection of Georgia for providing various datasets used in this study, and the people of Mleta for the time spent with us explaining the dynamics of the events.

\section{References}

[1] Smith, K. (2004) Environmental Hazards: Assessing Risk and Reducing Disaster. Routledge, 306.

[2] Wisner, B., Blaikie, P., Cannon, T. and Davis I. (2004) At Risk: Natural hazArds, People’s Vulnerability and Disasters. Psychology Press.

[3] Bankoff, G., Frerks, G. and Hilhorst, D. (2004) Mapping Vulnerability: Disasters, Development and People. Earthscan, London, 256.

[4] Gaillard, J.C. (2010) Vulnerability, Capacity and Resilience: Perspectives for Climate and Development Policy. Journal of International Development, 22, 218-232. http://dx.doi.org/10.1002/jid.1675

[5] Delica-Willison, Z. and Willison, R. (2004) Vulnerability Reduction: A Task for the Vulnerable People Themselves. Mapping Vulnerability: Disasters, Development and People. Earthscan, London, 145-158.

[6] Peacock, W.G., Brody, S.D. and Highfield W. (2005) Hurricane Risk Perceptions among Florida's Single Family Homeowners. Landscape and Urban Planning, 73, 120-135. http://dx.doi.org/10.1016/j.landurbplan.2004.11.004

[7] Prelog, A.J. and Miller, L.M. (2013) Perception of Disaster Risk and Vulnerability in Rural, Texas. Journal of Rural Social Sciences, 28, ().

[8] McCall, M.K. (2008) Participatory Mapping and Participatory GIS (PGIS) for CRA, Community DRR and Hazard Assessment. ProVention Consortium, CRA Toolkit, Participation Resources, Geneva.

[9] Marty, C., Korup, O., Margret, P.M. (2009) Mountains and Climate Change: From Understanding to Action. In: Kholer, T. and Maselli, D., eds. Mountain Hazards, Geographica Bernensia and SDC, Centre for Development and Environment (CDE), Bern, 31-40.

[10] Tran, P., Shaw, R., Chantry, G. and Norton, J. (2009) GIS and Local Knowledge in Disaster Management: A Case Study of Flood Risk Mapping in Viet Nam. Disasters, 33, 152-169. http://dx.doi.org/10.1111/j.1467-7717.2008.01067.x

[11] Krishnamurthy, P.K., Fisher, J.B. and Johnson, C. (2011) Mainstreaming Local Perceptions of Hurricane Risk into Policymaking: A Case Study of Community GIS in Mexico. Global Environmental Change, 21, 143-153. http://dx.doi.org/10.1016/j.gloenvcha.2010.09.007

[12] Peters-Guarin, G., McCall, M.K. and van Westen, C. (2012) Coping Strategies and Risk Manageability: Using Participatory Geographical Information Systems to Represent Local Knowledge. Disasters, 36, 1-27.

[13] Rød, S.K., Botan, C. and Holen, A. (2012) Risk Communication and Worried Publics in an Imminent Rockslide and Tsunami Situation. Journal of Risk Research, 15, 645-654.

[14] World Bank (2013) Building Resilient Communities: Risk Management and Response to Natural Disasters through Social Funds and Community-Driven Development Operations. The World Bank, Washington DC.

[15] UN-ISDR: Living with Risk, UN, 2004.

[16] National Environmental Agency, NEA (2011) Information Bulletin on Outcomes of Geological Disasters in 2010 and Forecast for the 2011 Year in Georgia. Department of Geology, Ministry of Environmental Protection and Natural Resources, Tbilisi.

[17] Tsagareishvili, N. (2011) Lives of Eco-Migrants under Threat. http://www.humanrights.ge/index.php?a=main\&pid=13292\&lang=eng\&page=1

[18] Liebenberg, L. (2012) The Cyber Tracker Story. http://cybertracker.org/background/our-story

[19] Spanu, V. and McCall, M.K. (2013) Eliciting Local Spatial Knowledge for Community-Based Disaster Risk Management: Working with Cyber Tracker in Georgian Caucasus. International Journal of E-Planning Research (IJEPR), 2, 45-59. http://dx.doi.org/10.4018/ijepr.2013040104 
[20] Shall, N. and Becker, M. (2008) Practitioner’s Guide: Conflict Analysis_Participatory Local Conflict Analysis, South Caucasus. Copyright: GTZ-FRCS Project Team, 21 p.

[21] Melsbach, G., Fuhr, S. and Baghdadze, A. (2010) Ex-Post Evaluation 2010—Brief Report Promotion of Food Security, Regional Cooperation and Stability in the Southern Caucasus, Armenia, Azerbaijan and Georgia (FRCS). Deutsche Gesellschaft für Internationale Zusammenarbeit (GIZ) GmbH.

[22] CARE: South Caucasus, 2010. www.care-international.org

[23] TJS (Transboundary Joint Secretariat), 2012. www.tjs-caucasus.org/

[24] UNECE (United Nation Economic Commission for Europe), 2009.

http://aarhusclearinghouse.unece.org/resources/www.madridparticipa.org/?sortby $=$ da \&c $=1000002 \& c=\& c=1000014 \& c$ $=1000024$ 